\title{
Openness and Opacity: An Interview with Clare Birchall
}

FRANCIEN BROEKHUIZEN, Coventry University

SIMON DAWES, Université Paul Valéry, Montpellier

DANAI MIKELLI, Coventry University

POPPY WILDE, Coventry University

\begin{abstract}
In this follow-up interview to her keynote lecture at the MeCCSA-PGN 2015 Conference in Coventry, Clare Birchall discusses the "sharing economy", "shareveillance" and the depoliticised subjectivity shaped by both open and opaque data. In order to re-imagine subjectivity in the face of shareveillance, Birchall calls on Édouard Glissant's "right to opacity". Ultimately, she explains how the concept of "sharing" can be politicised as a Commons, while the appropriation of opacity can become a political act. Her reassessment of the politics and values associated with openness and secrecy has implications for media scholars, particularly in terms of the need to think more critically about what kinds of publishing, networks and communications we want to develop.
\end{abstract}

\section{KEY WORDS}

Data; Deconstruction; Interdisciplinarity; Neoliberalism; Opacity; Openness; Privacy; Secrecy; Shareveillance; Surveillance; Transparency 
THE EDITORS: To what extent has the relation between openness and opacity, or between transparency and secrecy, been of particular interest to media scholars investigating surveillance, the 'sharing economy' and digital media? And would you say that there has been a tendency among scholars to reduce this relation to a binary in which transparency is privileged?

CLARE BIRCHALL: The relation between openness and opacity has been an implicit rather than explicit concern of scholars of surveillance and digital media, although there has always been an interest in the limits and politics of both visibility and visuality. What I am trying to do is bring the relation between openness and opacity into the foreground as a way of thinking through the data subject today. It's not so much that scholars have privileged transparency, as you put it, but rather that there is a general cultural celebration of transparency and much faith is put in it as a solution to complex socio-political problems. We only need to think of the number of times "being more transparent" is cited as a remedy in the public sphere. The danger with this is that transparency can simply make inequitable systems and distributions more efficient. It can be offered in lieu of accountability and trust rather than foster a culture that takes these responsibilities seriously. The risk is that transparency alone does nothing to challenge the political settlement. Therefore, understanding transparency as a form of obfuscation itself can do much to destabilise a culturally endorsed binary opposition.

THE EDITORS: Rather than treating openness and opacity as a binary, and making assessments in terms of degrees of one or the other, you treat the relation between them as a starting point, and critically engage with the tensions between the two concepts. To what extent do you argue that the relation between them is better understood as a symbiotic, mutually constitutive dialectic, and what theoretical perspectives or disciplines do you draw on to elaborate this relation?

CLARE BIRCHALL: One way to rethink the issue is to posit visibility as a unified category for the social sciences, as Andrea Brighenti does. This way, both secrecy and transparency (and other variations like invisibility, anonymity, revelation, confession etc.) can be thought as vectors within a certain 'distribution of the sensible', as Jacques Ranciere would have it. For Ranciere, every distribution amounts to a particular delimitation of space, time, the visible, the sayable, the audible, and political experience. I've been trying to think of secrets and transparency as not wholly distinct operations within a distribution of veillance and cognition. In light of this, it very much matters not only what is secret, but how it is secreted; and equally not only what is open, but what form that openness takes.

Jacques Derrida's work on the secret has also been crucial to the way I've thought about the relation between secrecy and transparency. Transparency cannot easily tolerate singularity in the form of those who want to be exempt from its call: those who want to maintain a right to the secret. Such intolerance for singularity/secrecy means that transparency risks looking less like an agent of democracy and freedom and more like a tool of totalitarianism. Dave Eggers' The Circle is a good, if not terribly subtle, illustration of this. Without the right to retreat from the demands of transparency, the freedom assured by democracy is infringed. But equally, the refusal to come forth and be counted is antithetical to the idea of democracy. And so, when considered in relation to democracy, we have to think of secrecy and transparency as both that which makes democracy possible and, at the same time, impossible. Thus, the choice between them is infinitely undecidable. 
THE EDITORS: Is there a danger of relativism in adopting such a nuanced approach to the open-opaque dichotomy? How do you account for power in this fluid framework, and to what extent are you interested in transcending the limitations of the ideology critique of secrecy and transparency?

CLARE BIRCHALL: For me, deconstructive approaches do not lead to relativism because of the way Derrida invokes the 'decision' that must be made in the face of undecidability. Rather than foreclosing questions of politics or power, the aporia of transparency-as-secrecy and secrecy-as-transparency means that decisions, or what Sarah Kember and Joanna Zylinska call ethical 'cuts', must be made, even when those decisions hold the trace of their own undecidability. Equally, a responsible decision, regarding say, the positive or negative value of either secrecy or transparency, must be made without referring to a pre-given, already known, way of knowing and understanding. If we just follow in an already known path, make a programmatic decision, we affirm our own subjectivity and knowledge, and in doing so devolve responsibility to an already decided, calculable way of deciding. Derrida explains, 'When the path is clear and given, when a certain knowledge opens up the way in advance, the decision is already made, it might as well be said that there is none to make: irresponsibly, and in good conscience, one simply applies or implements a program'. In light of this, we could say that when transparency is celebrated and secrecy derided (except when articulated to security), an 'irresponsible' decision is being operationalised because it has been made according to an already established programme and logic.

Obviously, reversing the terms of that opposition to celebrate secrecy and deride transparency risks being just as programmatic. Nevertheless, I think ideology critique has a part to play when thinking about secrecy and transparency. For example, I think it's important, as others have done, to expose transparency's complicity with neoliberal formations. It is always important to highlight what is obfuscated by apparently apolitical, post-political, or panideological terms like 'transparency'. Equally, it's important to show how secrecy has been articulated to and by securitisation. But these moves are only the first stage. After we have a picture of the secrecy-transparency assemblage, then we must make decisions, employ tactics, make interventions. In very different ways, Eve Kosofsky Sedgwick, Jodi Dean, Žižek, and Baudrillard among others, all remind us that revelation (of ideology, of scandal) is never enough in itself.

THE EDITORS: You claim to not attempt to resolve the tension between openness and opacity, but to rather 'inhabit them strategically', to interrogate transparency, 'rehabilitate' secrecy, and reclaim a 'right to opacity'. What does such an act entail, and in what way is it a political act?

CLARE BIRCHALL: I want to make an intervention into the political and cultural values that have been ascribed to contemporary invocations of both secrecy and transparency. As a first gesture, this involves reversing the binary - to see what it would mean to think about opacity as a position or tactic that the Left could use as an alternative to neoliberal articulations of transparency. This appropriation of the secret is intended to wrest the secret from the securitising nature of the state. Rather than a democratisation of knowledge, a democratisation of the content of secrets, as transparency promises (and fails) to implement, I want to experiment with a democratisation of the secret as form. I turn to the Martinican philosopher Édouard Glissant to think through the politicality of this. 
In his writing, Glissant is concerned with a 'right to opacity' as a way of resisting being reduced and essentialised by the demand to be understood and for universal truths to be applied to all. While the idea of 'difference' has facilitated recognition of minorities, it too 'can still contrive to reduce things to the Transparent', Glissant writes. Glissant regards the emphasis on understanding as the basis of progressive politics to be a Western demand for transparency. The Other, in this tradition, is constructed as an object of knowledge.

Glissant advocates instead a model of relationality that does not rest on the false promise of total understanding and absolute truths. 'The opaque is not the obscure ...' he writes. 'It is that which cannot be reduced, which is the most perennial guarantee of participation and confluence.'

Glissant's secret interrupts an identity politics that appears open and progressive but that in fact determines possible social identities, discursive parameters and modes of relationality. The imperative to be known leaves the object of knowledge unable to be other. Whereas calls for 'privacy' focus on the rights of sovereign individuals and seem antithetical or irrelevant to collective politics, Glissant's 'right to opacity' allows for relationality not based on sanctioned identities and ways of understanding. In this relation, we would be able to conceive of the opacity of the other for us, without reproach for our opacity to the other.

I want to borrow this 'right to opacity' from the realm of identity politics for my own concern with state surveillance and secrecy. Rather than acts of publicity such as legal marches or online petitions, we might need to meet the pervasive protocols of inequitable dataveillance employed by the securitised state with opacity. A right to opacity in this context would mean the demand not to be reduced to and understood as data as defined by the state. Though we have to acknowledge the attendant risks of non-progressive and criminal activity made possible by the 'dark' web, it is nevertheless here that the right to opacity might be asserted.

And so, for anyone interested in alternative visions of the political settlement, experimenting with secrecy rather than jumping on the bandwagon of transparency might offer more productive possibilities. On the one hand, this might mean obscuring one's digital shadow to avoid state and consumer surveillance, and dis-align oneself from the form of subjectivity configured by a relationship with open data that is circumscribed by neoliberal formations. On the other, it might involve a reconceptualization of rights and responsibilities when it comes to the demand that everyone must 'come forth' and account for themselves; how we relate to and read others within a discourse that has already decided what is and what is not possible and knowable.

Appropriating the secret becomes part of a political project that attempts to decentralise the right to look as well as recalibrate the cultural values attached to openness and opacity. The latter is essential given its dominant articulation to the state and its surveillance and intelligence capacities.

But as I say, this is only a tactical first step. The next step is to deconstruct the opposition between transparency and secrecy.

THE EDITORS: Acknowledging that we live in an age of transparency advocacy, you argue in favor of radical forms of transparency. You suggest thinking about radical transparency in 
terms of politics and through the lens of a resistant methodology, and not as another mechanism of neoliberal control. Could you expand on this approach?

CLARE BIRCHALL: When neoliberal formations and mechanisms make their existence seem commonsensical and inevitable, it is difficult to imagine and experiment with alternatives. It may well be that transparency is too thoroughly embedded within a neoliberal assemblage to be of much use for the Left, but I would still hope that there are forms of veillance and 'seeing through' worth investing in. In this way, it may be that secrecy or opacity is a tactical step on the way to recalibrating transparency in more horizontal, equality affirming, otherness-respecting versions.

In business schools, 'radical transparency' refers to an organisation that implements total openness at all levels of operation. I want to appropriate the term as one that can point to a shift in politics rather than scale, as you say. In doing so, I want radical transparency to have an effect beyond the prescribed role that revelations usually have within the public sphere.

WikiLeaks, we might say, provides a model for such a 'radical transparency'. WikiLeaks trades in instances of forced rather than voluntary acts of transparency - leaks that place in the public domain data and information that alters the political stakes, reconfigures the parameters of the known and unknown in ways that have the potential to prompt change. However, WikiLeaks has continuously been framed, and I would argue contained, by Julian Assange's own insistence (albeit for legal and strategic reasons) that WikiLeaks is a media outlet. When Assange makes statements such as, "The swirling storm around WikiLeaks today reinforces the need to defend the right of all media to reveal the truth," the singularity of WikiLeaks is underplayed in order to seek the legal protection offered to more traditional print media.

What might be most radical about WikiLeaks is that it reminds us that there are other versions of transparency in which we can invest. Rather than describing what WikiLeaks is, 'radical transparency' might instead be a term for something yet to arrive. 'Radical transparency' would have to challenge the ways in which we are positioned and how we understand ourselves to be surveilled data objects. It would have to perform a mode of revelation not aligned with cultural, economic and political forms of neoliberalism. It would need to politicise data, transparency, and openness in general - to ask what role revelation should play in democratic representation.

In terms of technology, 'radical transparency' might give rise to platforms and programmes that can provide more context for open data - stating explicitly the value of open data (to whom or what), or the conditions under which it was collated. It might involve communications technologies that enable large scale sociality to ensure that transparency is horizontal rather than top-down. A radical transparency would have its eye on the structural inequalities behind the digital divide and technological literacy, rather than assuming that making data available, or transparency in general, is political in and of itself.

THE EDITORS: Finally, it would be interesting to know how and when you first became interested in these questions, and how your approach to transparency and secrecy has changed over time.

CLARE BIRCHALL: I actually wrote my MA dissertation on secrecy and my $\mathrm{PhD}$ thesis on conspiracy theory (which then became the subject of my first book). The MA thesis in 
particular was mainly focused on literature, culture and media, working out of an English Department as I then was. I would say that my interests have been expanded by interdisciplinary encounters. My time in the sociology department at Kent University, for example, has brought me closer to the world of policy and politics. And my move to King's has brought me into contact with International Relations. Working on transparency, I've been invited to speak at events centred on the Law, Business, History, as well as Aesthetics. All of these encounters have deepened my understanding of transparency and secrecy and pushed me in unexpected directions. I recently attended an excellent event on security at Uppsala University in Sweden, which has started a project on the ways in which secrecy is articulated to and by securitisation. But also, as the art world has responded to the current concern with secrecy and transparency, I've been invited to speak at galleries and write for catalogues, which has made me address questions of aesthetics and politics. I think the constant in all of this, as well as a commitment to interdisciplinarity, is a deconstructive approach, holding on to the aporia of transparency-as-secrecy and secrecy-as-transparency.

Clare Birchall is a Senior Lecturer in the English Department at King's College London. She is the author of Knowledge Goes Pop: From Conspiracy Theory to Gossip (Berg, 2006) and co-editor of New Cultural Studies: Adventures in Theory (Edinburgh University Press, 2007). She has also edited special issues of the journals Theory, Culture and Society and Cultural Studies. Her most recent research is concerned with the relationship between secrecy and transparency in the digital age and she is part of an ESRC grant to fund a series of research seminars on such issues entitled 'DATA - PSST! Debating and Assessing Transparency Arrangements - Privacy, Security, Surveillance, Trust'.

Alongside more traditional scholarship, Birchall is involved with a number of digital projects. She is one of the editors for the online journal Culture Machine; an editorial board member and series co-editor for the Open Humanities Press; and part of the team behind the JISCfunded Living Books About Life series.

Email: clare.birchall@kcl.ac.uk 